\title{
Quasi-Real Scenario of Reconfigurable Filtering Functions Antenna for UWB Communications
}

\author{
Hicham Medkour ${ }^{1}$, Ameur Zegadi ${ }^{1}$, Erika Vandelle ${ }^{2}$, Imededdin Djadour ${ }^{3}$, Vuong Tan $\mathrm{Phu}^{2}$ \\ ${ }^{1}$ LCCNS, Department of Electronics, Ferhat Abbas University of Setif 1, \\ Compus El-Maabouda, 19000 Setif, Algeria \\ ${ }^{2} I M E P-L A H C$, Grenoble INP - MINATEC, \\ 3, Parvis Louis Neel - CS 50257 - 38016 Grenoble Cedex 1, France \\ ${ }^{3}$ ETA, Department of Electronics, University of Mohamed El Bachir El Ibrahimi, \\ El-Annasser, 34030, BBA, Algeria \\ medkour_h19@univ-setif.dz
}

\begin{abstract}
In this paper, an Ultra Wide Band antenna with reconfigurable filtering-characteristic is proposed to overcome interferences problems in the frequency range $3.1 \mathrm{GHz}-$ 10.7 GHz. With dimensions of $35 \times 35 \mathrm{~mm}^{2}$, the structure is simple, low-cost and possesses an operating bandwidth from $3 \mathrm{GHz}$ to $12 \mathrm{GHz}$. Besides, it is easy to reconfigure this antenna to filter one, two or three interferences, in which the filtering is achieved by three slots of half wavelength created in the geometry, while the reconfiguration is achieved through four PIN diodes used to control the three slot's effect. Considering the filtering action, this antenna can switch between eight distinct operational modes, which is the highest number compared to previous works. Design and analysis of the proposed configuration are done by two simulation software which are CST and HFSS. The acceptable agreement between the results obtained by both simulations proves the realistic working performance of the proposed structure. The present antenna is suitable for UWB communication applications, particularly; the which are suffering from interference issues with WiMAX $3.3 \mathrm{GHz}-3.7 \mathrm{GHz}$, WLAN $5 \mathrm{GHz}-5.3 \mathrm{GHz}$ or ITU band 8 GHz- 8.4 GHz.
\end{abstract}

Index Terms-Filtering; Interference; PIN diodes; Reconfiguration; UWB antenna.

\section{INTRODUCTION}

Recently, the frequency band from $3.1 \mathrm{GHz}$ to $10.7 \mathrm{GHz}$, called Ultra-Wide Band (UWB) spectrum has been of great interest, since it is the band where data can be transmitted with high rate, low power consumption, low-cost, less obstacles penetration and so on [1], [2]. Because of these attractive properties, the number of applications performing in these bands is increasing rapidly these days, which unfortunately led to crowd this interesting part of spectrum and undesirable problem of interferences has emerged. Interferences that have been caused by some narrow bands considerably disturb the functionality of UWB systems and lower their performance.

For this reason, implementation of a filtering function into UWB systems is crucial to overcome interference issues; however, it is preferable not to introduce additional size into the UWB system circuitry, because miniaturization of today's wireless communication systems is strongly needed.

Manuscript received 5 February, 2018; accepted 17 July, 2018
Instead, it is much better if one can assign the filtering function to the antenna since the latter is a vital element for any wireless communication system; hence the antenna can perform the filtering operation without the need for integrating filtering circuits. This can help to get rid of additional size and complexity. Many papers have been published lately to propose different shapes of UWB antennas with the ability to filter up to five interfering bands from the UWB spectrum as in [3]-[6]. The filtering provided by those designs is perpetual, which means a significant part of the spectrum is always out of work (filtered). This is a clear drawback particularly once interferences are not active. Alternatively, it is worthwhile if one can design an UWB antenna that is capable of controlling its filtering action, like activating and deactivating the filtering or shifting its frequency. Unlike perpetual filtering, this could strongly help to efficiently exploit the UWB spectrum. This procedure is referred to as "reconfigurable filtering" and it has been a topic of many active researches in the last period.

In the literature, different shapes of UWB antennas with reconfiguration of single filtered bands have been reported in [7]-[10]. Then, it has been the goal to increase the number of filtering bands like in [11]-[14], in which UWB antennas with reconfiguration of two interferences are successfully implemented. Furthermore, UWB antennas with up to four reconfigurable interfering bands have been reported in [15] and [16]. A key mechanism to achieve filtering reconfiguration has been followed in these works, in which various kinds of switches, including PIN diodes, MEMS, FET transistors, Shotcky diode and optical switches have been used. However, less attention has been paid to the effect of the quantity of switches on the antenna size and functionality. As it is known, the more switches the antenna has, the bigger its size is. Here lies the weakness of the previous works, since more switches have been used to produce less filtering operational modes. Typically, $n$ switches can contribute to $2^{n}$ operational filtering modes. For this reason, the present work has come to limit this drawback. Actually, a part of this work has been initiated and published in [17]. The objective is to design a compacted size UWB antenna capable of producing more 
filtering operational modes, while using a smaller number of switches. As presented in the subsequent sections, the proposed antenna is thoroughly studied using two simulation software CST and HFSS. The results gotten are discussed while performance is presented and compared to that of previous works.

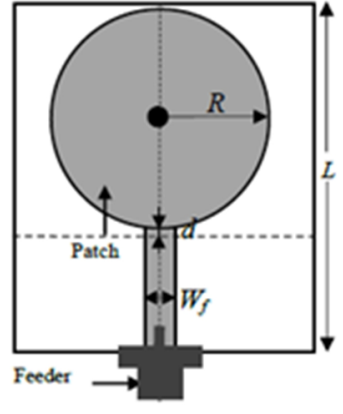

Antenna 1 (a)
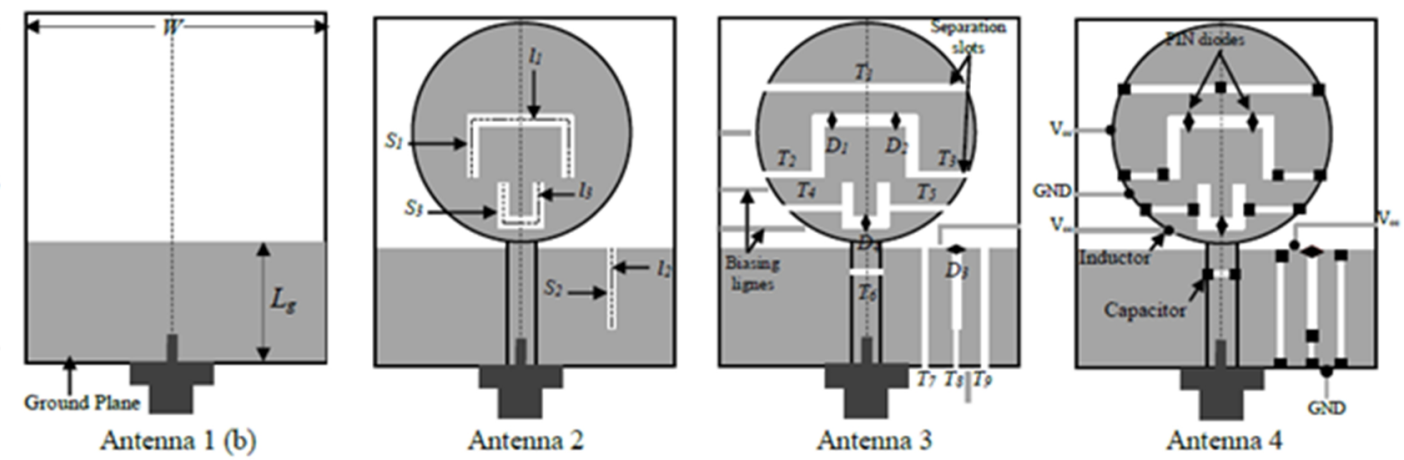

Fig. 1. Design and optimization steps: (a) top view; (b) lower view.

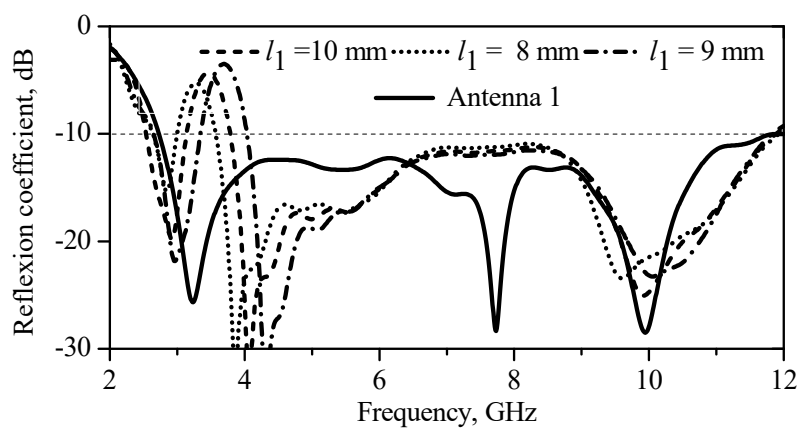

(a)

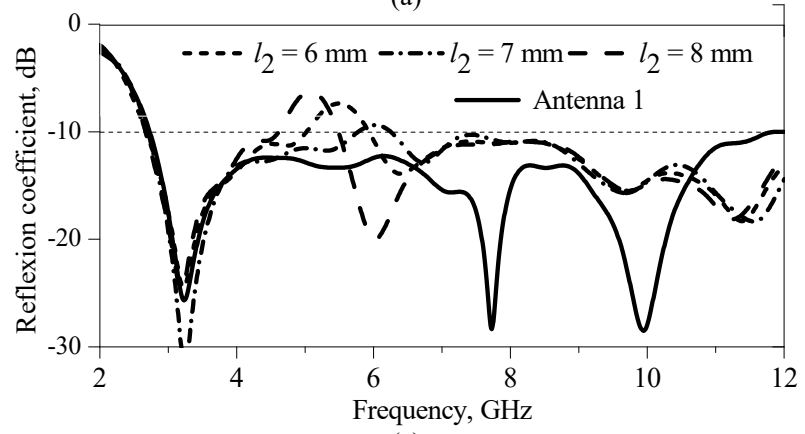

(c)

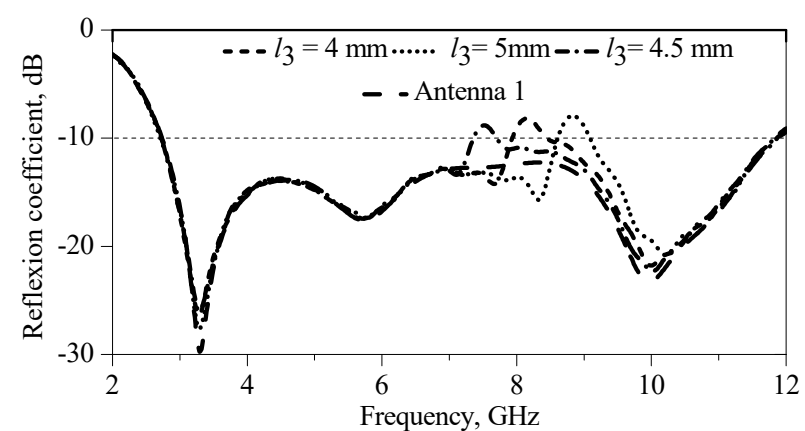

(b)

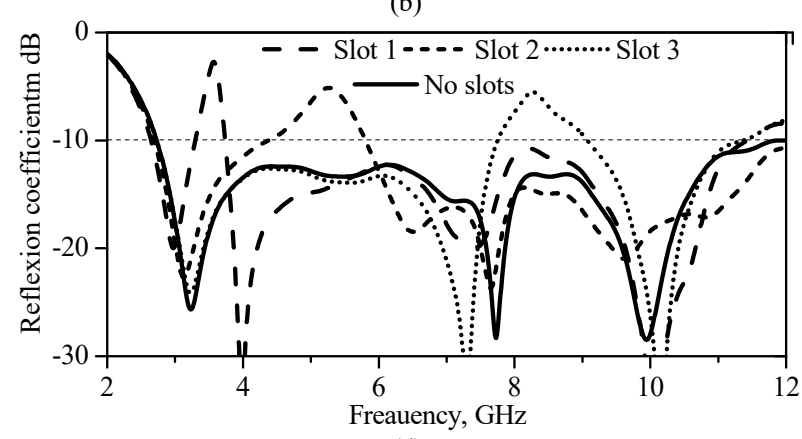

(d)

Fig. 2. Design and optimization step: a) Optimization of $l_{1}$, b) Optimization of 12, c) Optimization of 13, d) The individual effect of each slots.

\section{DESIGN MEthodology}

In order to investigate the proposed reconfigurable filtering system, the printed monopole UWB structure is chosen. Because it satisfies the requirements for UWB applications such as wide bandwidth, omnidirectional radiation pattern, high gain and low-cost of implementation and so on [2]. As shown in Fig. 1 (Antenna 1), the proposed structure consists of a circular patch with radius $R$ fed by a $50 \mathrm{Ohm}$ micro-strip line of width $W_{f}$ printed on the upper face of the FR-4 substrate with permittivity $\varepsilon_{r}=4.4$ and thickness $1.5 \mathrm{~mm}$. The ground plane with the length $L_{g}$ is printed on the lower face of the substrate. The latter has overall dimensions of $W \times L$. Using Computer Simulation Technology software [18] through time domain solver calculations, the basic structure design and optimization are done while a careful parametric refinement is owned particularly to the parameter $d$ in order to obtain an ultrawide band characteristic. Given the fact that, the antenna resonance and radiation properties are due to a certain current distribution within the geometry, filtering functions can be created by occurring new current paths in the patch and ground plane, which will mismatch the antenna resonance at particular frequencies within the UWB spectrum $3.1 \mathrm{GHz}-10.6 \mathrm{GHz}$. Based on that, a parametric study is carried out in which three slots $S_{1}, S_{2}, S_{3}$ of width $0.5 \mathrm{~mm}$ each are created in the patch and the ground plane as shown in Fig. 1 (Antenna 2). The concept followed to predict the primary slot's length is shown by equation under [19]

$$
\lambda_{g}=\frac{c}{f_{c} \times \sqrt{\varepsilon_{\text {reff }}}} .
$$

in which $\lambda_{g}$ is the guided wavelength in $m, c$ is the light speed in $\mathrm{m} / \mathrm{s} . f_{c}$ is the central frequency of the filtered band in $\mathrm{GHz}$ and $\varepsilon_{\text {reff }}$ is the effective dielectric constant. Hence, the filtering functions are obtained at $l_{1}=12 \mathrm{~mm}, l_{2}=12 \mathrm{~mm}$ and $l_{3}=10.39 \mathrm{~mm}$. Afterwards, several parametric calculations have been performed using CST in order to refine the positions and the lengths of each slot separately. The influences of $l_{1}, l_{2}$ and $l_{3}$ on the filtering actions can be well observed in Fig. 2, in which the behaviours of the antenna with and without slots are presented for comparison. 


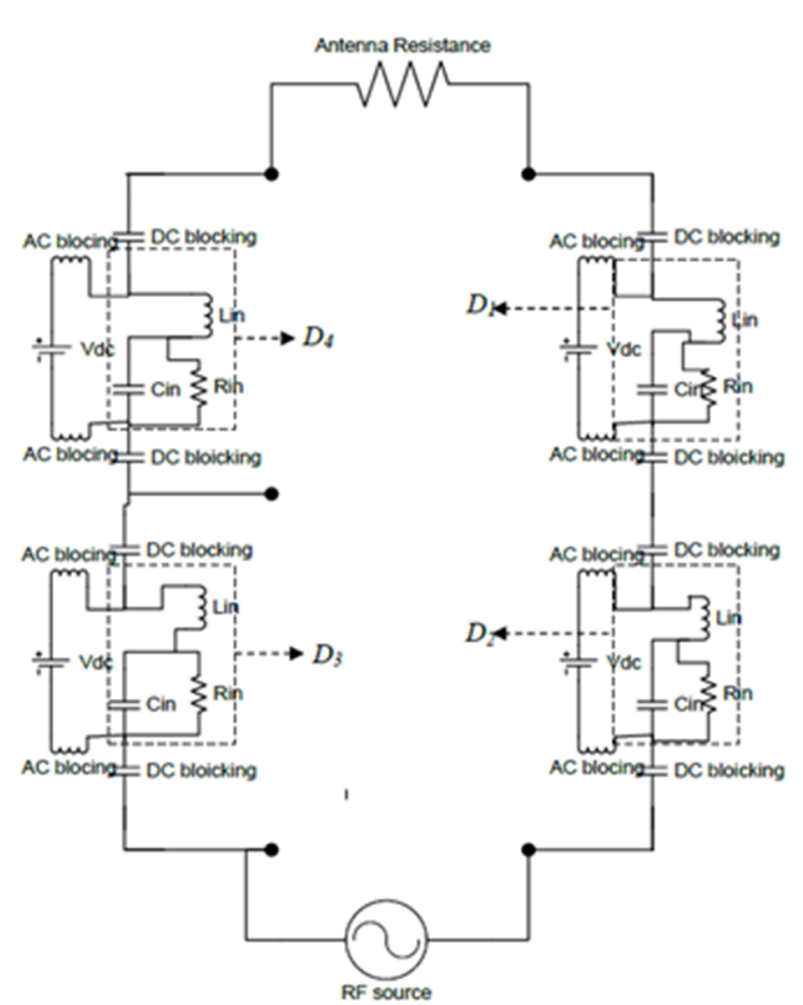

(a)

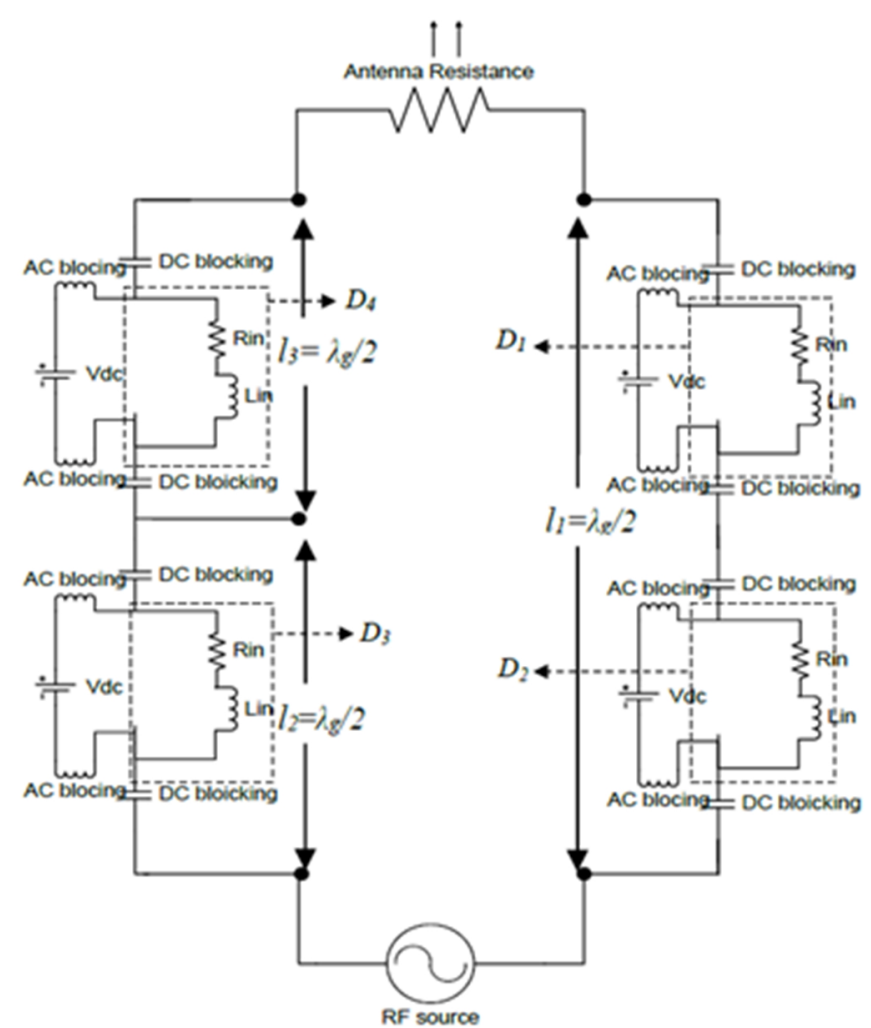

(b)

Fig. 3. Modelling of the diodes across the slots: (a) forward biasing $\mathrm{V}_{\mathrm{dc}}>0$ (mode 1); (b) reversed biasing $\mathrm{V}_{\mathrm{dc}}<=0$ (mode 8).

The filtering operations are controlled by monitoring the effects of the slots, across which, four PIN diodes $D_{1}, D_{2}, D_{3}$ and $D_{4}$ are carefully positioned as shown in Fig. 1 (Antenna 3). Each PIN diode has to be controlled through a biasing circuit that necessitates a DC signal $\left(V_{\mathrm{DC}}\right)$. The diode can be set $O n$ when it is forwardly biased and Off when inversely biased. To explain the diodes functionality along with the biasing control, the equivalent circuit model RLC are given in Fig. 3. When the diodes are forwardly biased $\left(V_{\mathrm{DC}}>0\right)$, they shows high capacitance which allows passing AC signals, where each diode is modelled by capacitor in parallel with a small resistor, Fig. 3(a). Otherwise, they shows a high resistance to AC signals when reversely biased $\left(V_{\mathrm{DC}}<=0\right)$ and they are modelled only by a serial resistor, as shown in Fig. 3(a) and Fig. 3(b). In simulation, Sparameters of BAR50-2V PIN diodes [20] are introduced using CST design studio. These diodes are commercially available with low-cost and with the suitable size and operating frequency for the present application. They are used in this design, in order to predict the practical behaviour of the proposed antenna rather than conventional simulation with ideal switches such as metallic stubs. Sparameters file includes the modelling of the diodes in the On and Off states. Besides, it is crucial to separate between the DC signals and the AC signals within the antenna surfaces. For this reason, a set of slots $T_{1}$ to $T_{6}$ is generated in the patch to prevent the DC signals from circulating in the entire patch surface, where $T_{7}, T_{8}$ and $T_{9}$ are created in the ground plane for the same reason, Fig. 1 (Antenna 3). In fact, these separations have heavily changed the antenna basic resonance; this is why a set of RF capacitors of $\mathrm{C}=22$ $\mathrm{pF}$ is inserted across the two ends of each biasing slot, as observed in Fig. 1 (Antenna 4). As it is known, capacitor stops DC signals while lets pass AC signals if it has small capacitive reactance $X_{\mathrm{c}}$. for this reason, its value is chosen to be $\mathrm{C}=22 \mathrm{pF}$ to achieve less capacitive reactance value where: $X_{\mathrm{c}}=1 /(2 л f C)$. Furthermore, inductors of value $27 \mathrm{nH}$ and operating frequency $2.4 \mathrm{GHz}$ are used to prohibit alternative signals from flowing towards the biasing circuit. For that, the value $\mathrm{L}=27 \mathrm{nH}$ is calculated to achieve high inductive reactance where $X_{\mathrm{L}}=2 \pi f L$. Finally, the optimization of Antenna 4 has been conducted in CST based on the criteria that, the reflexion coefficient is close to $-5 \mathrm{~dB}$ over the filtered bands, while it is less than $-10 \mathrm{~dB}$ over the rest parts of UWB spectrum. The final optimized dimensions are depicted in Table I.

TABLE I. ANTENNA DIMENSIONS.

\begin{tabular}{|c|c|c|c|}
\multicolumn{1}{c|}{ TABLE I. ANTENNA DIMENSIONS. } \\
\hline Parameter & $\begin{array}{c}\text { Value in } \\
\text { millimeters }\end{array}$ & Parameter & $\begin{array}{c}\text { Value in } \\
\text { millimeters }\end{array}$ \\
\hline$W$ & 35 & $d$ & 0.5 \\
\hline$L$ & 35 & $l_{1}$ & 52 \\
\hline$W_{f}$ & 3 & $l_{2}$ & 6.5 \\
\hline$R$ & 6 & $l_{3}$ & 10.39 \\
\hline$L_{g}$ & 12 & & \\
\hline
\end{tabular}

\section{RESUlTS AND DISCUSSION}

The control of the four PIN diodes is well clarified in Table II, in which eight possible switching states are exposed. Due to the longer length of S1 compared to S2 and S3, one single diode was not enough to control its effect. Therefore, the two diodes $D_{1}$ and $D_{2}$ are incorporated to perform together like a single switch. Hence, the proposed antenna is capable of working in eight distinct operational modes, as illustrated in Fig. 4 that shows the simulation results obtained from CST for each mode. 

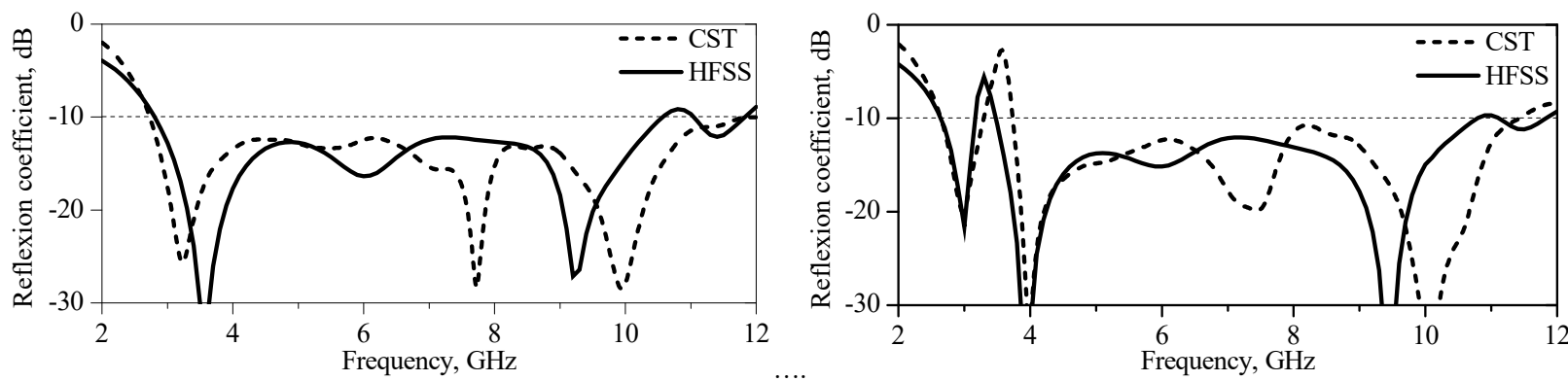

(a)

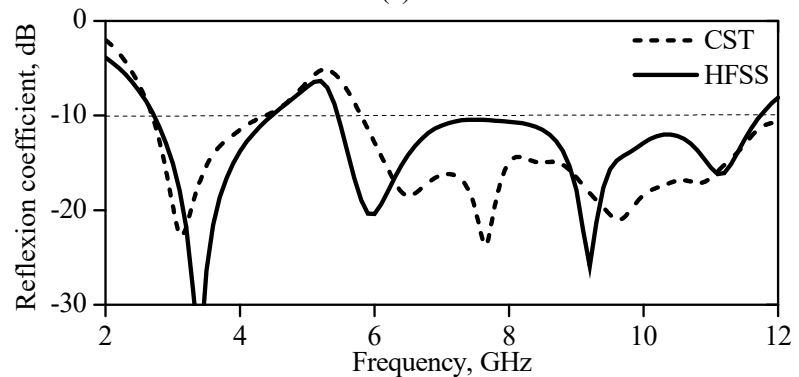

(b)

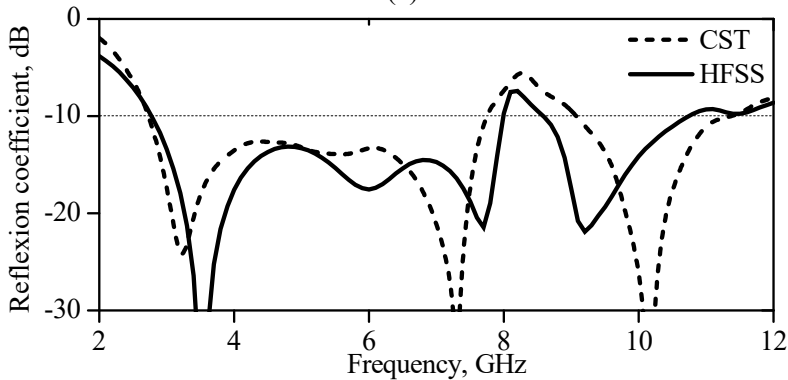

(c)

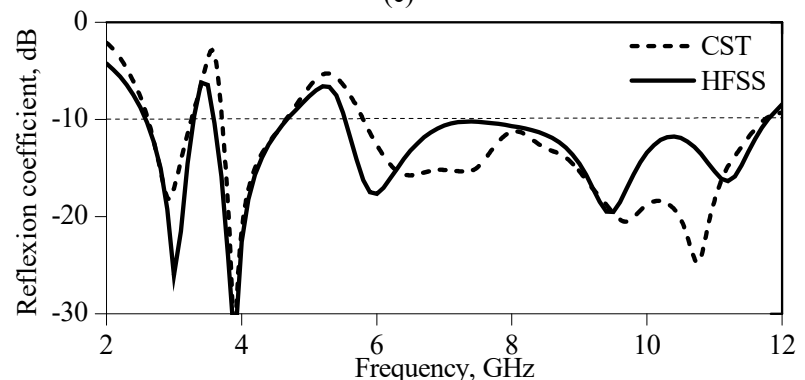

(d)

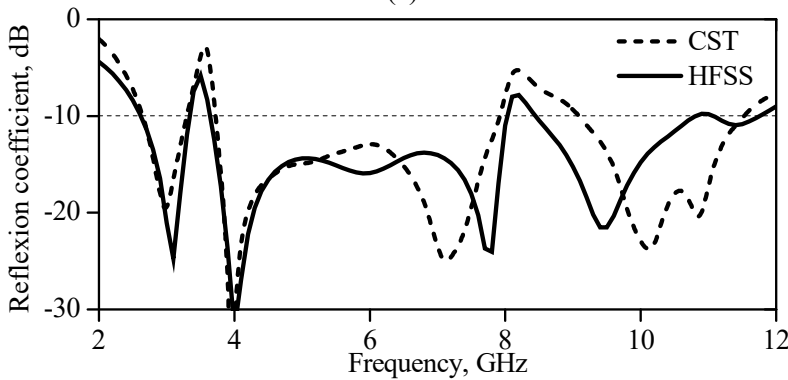

(f)

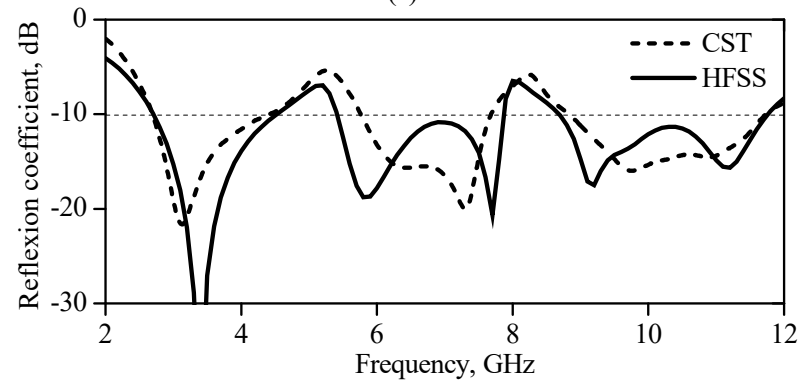

(g)

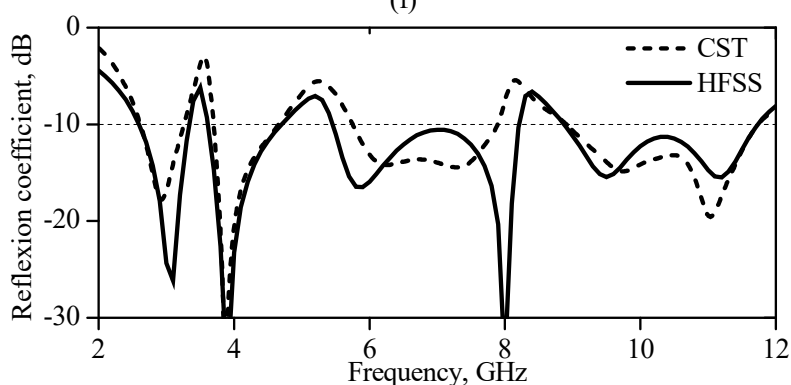

(h)

Fig. 4. Simulated reflexion coefficient of the eighth operational modes: (a) mode 1; (b) mode 2; (c) mode 3; (d) mode 4; (e) mode 5, (f) mode 6; (g) mode $7 ;$ (h) mode 8 .

For the eight different modes, the antenna tunes from $3 \mathrm{GHz} 11.5 \mathrm{GHz}$ which includes the UWB spectrum $3.1 \mathrm{GHz}-10.7 \mathrm{GHz}$. The filtering actions can be observed in the regions where the reflexion coefficient (S11) is around $-5 \mathrm{~dB}$. This reveals actually a high mismatching in the input impedance of the antenna which means in turn that, the antenna is prohibited from transmitting or receiving at the frequencies $3.5 \mathrm{GHz}, 5.1 \mathrm{GHz}$ and $8.2 \mathrm{GHz}$ in the modes 2, 3 and 4, respectively. This touch is used to stop interferences coming from WiMAX $(3.4 \mathrm{GHz}-3.7 \mathrm{GHz})$, lower band of WLAN ( $5 \mathrm{GHz}-5.4 \mathrm{GHz})$ and ITU band $(8 \mathrm{GHz}-8.4 \mathrm{GHz})$. Besides, the antenna can be reconfigured such as it filters two frequencies at once as in the modes 5, 6 and 7. Furthermore, it is capable to filter the three bands WiMAX, WLAN and ITU at the same time when it is in the mode 8 . In order to support the validity of the obtained results, the proposed structure is re-simulated using different simulation software which is HFSS [21]. As a result, the behaviours of both the methods appear like similar to each other for the eight modes, as shown in Fig. 4. This confirms the validity of the results obtained with CST.

\begin{tabular}{|c|c|c|c|c|}
\multicolumn{4}{|c|}{ TABLE II. REAL SWITCHES CONFIGURATION. } \\
\cline { 2 - 5 } & \multicolumn{4}{|c|}{ Switching states } \\
\hline \multirow{2}{*}{ Modes } & $\boldsymbol{D}_{\boldsymbol{1}}$ & $\boldsymbol{D}_{\boldsymbol{2}}$ & $\boldsymbol{D}_{\boldsymbol{3}}$ & $\boldsymbol{D}_{\boldsymbol{4}}$ \\
\hline mode 1 & On & On & On & On \\
\hline mode 2 & Off & Off & On & On \\
\hline mode 3 & On & On & Off & On \\
\hline mode 4 & On & On & On & Off \\
\hline mode 5 & Off & Off & Off & On \\
\hline mode 6 & Off & Off & On & Off \\
\hline mode 7 & On & On & Off & Off \\
\hline mode 8 & Off & Off & Off & Off \\
\hline
\end{tabular}

However, some discrepancies can be observed, particularly in the filtering levels obtained from HFSS. This can be explained by the fact that, in HFSS, metallic stubs 
were used as switches rather than S-parameters of real PIN diodes like in CST. To demonstrate the filtering functions, surface current distributions at the modes 1, 2, 3 and 4 are pictured in Fig. 5. It can be seen that, in the mode 1, the current distribution is quasi-uniform, since that by setting all the diodes in the On state, the effects of S1, S2 and S3 are not operational, Fig. 5(a). Unlike the mode 1, strong current distribution can be observed around S1, S2 and S3, attesting their contributions in the modes 2,3 and 4 , respectively Fig. 5(a)-Fig. 5(c).

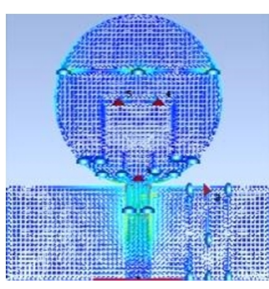

(a)

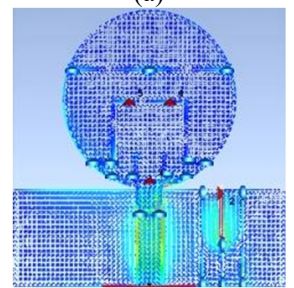

(c)

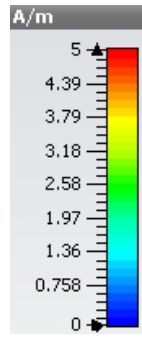

Fig. 5. Currents distribution on the antenna at: a) mode 1, b) mode 2, c) mode 3, d) mode 4 .

The radiation pattern of the mode 8 obtained by the CST simulation is presented for discussion in Fig. 6, since this mode includes all the filtering functions. It can be seen that, an omnidirectional shape is achieved in both $\mathrm{E}$ and $\mathrm{H}$ planes at all simulated frequencies. The same shapes of radiation pattern obtained with HFSS simulation confirm the ones obtained with CST. Nevertheless, higher gains are obtained with HFSS. This is due to the fact that, the effect of real switches is not considered. The realized gains of the antenna in the modes 1 and 8 are presented and compared in Fig. 7. The difference between the modes 1 and 8 can be clearly observed. In the mode 1, a quasi-steady peak gain between $2 \mathrm{dBi}$ and $3 \mathrm{dBi}$ is obtained while in mode 8 , the antenna gain exhibits a deep shrinking around the frequencies of $3.5 \mathrm{GHz}, 5.2 \mathrm{GHz}$ and $8.2 \mathrm{GHz}$. These attenuations in the peak gain can be explained by the antenna impedance mismatching due to the slot's effect. This result suggests that the filtering operations are successfully accomplished at these three frequencies of the spectrum.

\section{PERformances COMPARISON}

In order to highlight the contribution of this work, it is worth to compare the performance of the proposed antenna with other structures recently reported in the literature. The comparison is addressed in Table III, in which three key parameters are under consideration: the number of the RFswitches $(n)$, the operating modes $\left(2^{n}\right)$ and the size of the whole structure. As it is demonstrated, the antenna proposed in [13] has a size of about $40 \times 30 \times 0.8 \mathrm{~mm}^{3}$. It uses three PIN diodes $(n=3)$ to produce only four modes $(4 / 8)$. Otherwise, the antenna reported in [14] uses five optical switches $(n=5)$ while offering only four modes (4/32). It is size is larger considering the source of optical light. Up to six operational modes $(6 / 16)$ are provided by the antenna proposed in [15] where four $(n=4)$ ideal switches were used. Its size is presented in the table do not encompass the size of the biasing network. Therefore, the comparison divulges that the antenna of the present work outperforms those of previous works. It uses only four $(n=4)$ PIN to produce eight operational modes $(8 / 16)$ which is the highest that has been reported. Moreover, it has the smaller size including the basing network which is about $35 \times 35 \times 1.6$ $\mathrm{mm}^{3}$.
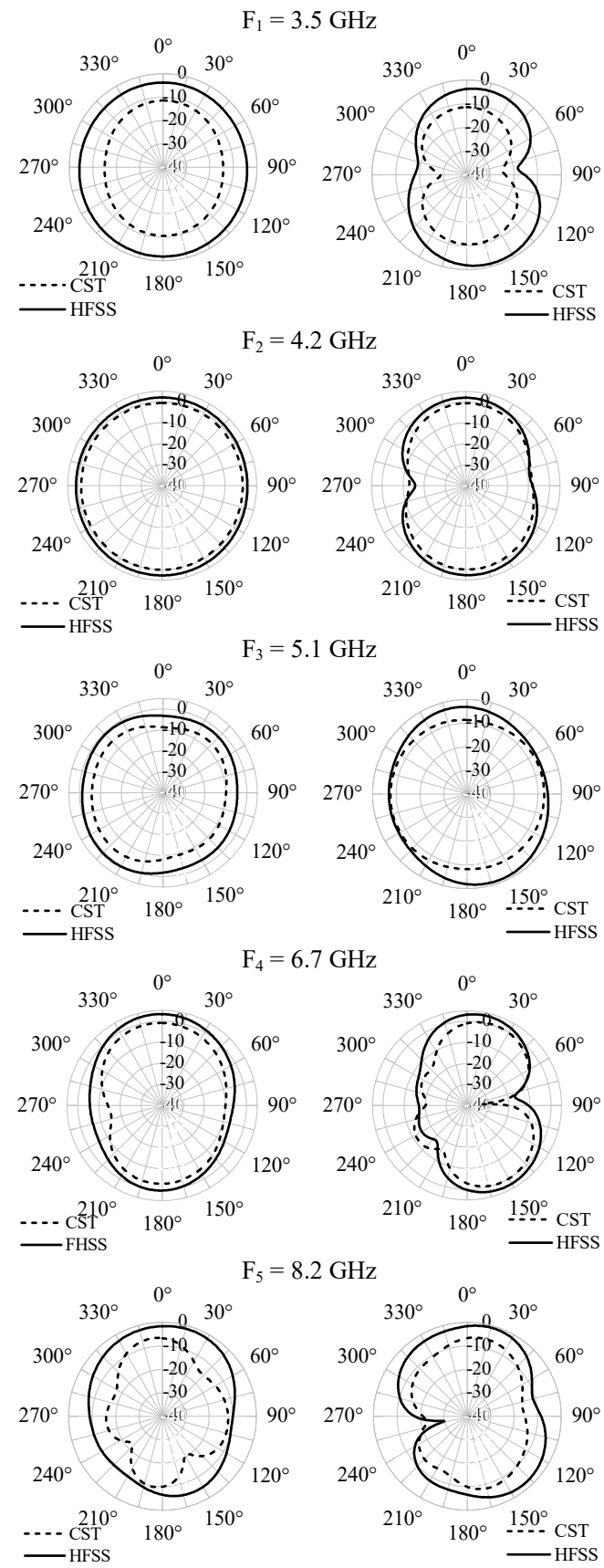

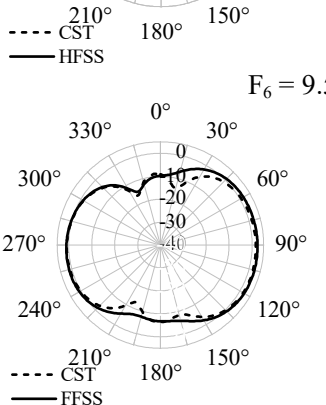

(a)

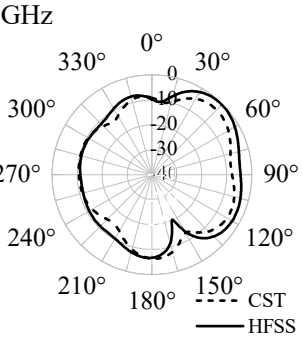

(b)
Fig. 6. Radiation pattern of mode 8 simulated in CST and HFSS: (a) Eplane $/\left\{\mathrm{Phi}=0^{\circ}\right\}$; (b) H-plane $/\left\{\mathrm{Phi}=90^{\circ}\right\}$. 


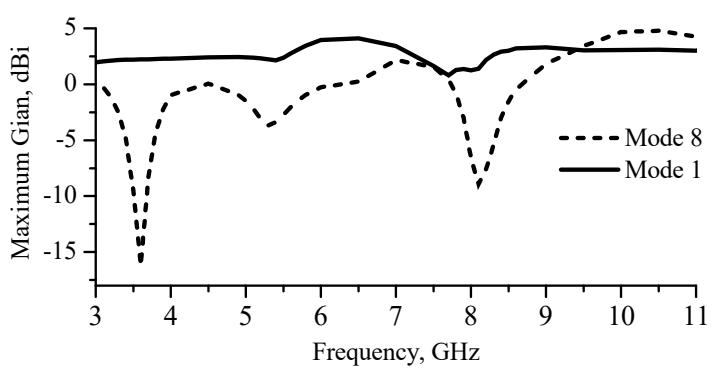

Fig. 7. Realized gain in dBi vs frequency in modes 1 and 8.

\begin{tabular}{|c|c|c|c|}
\hline Antenna & Operating modes $\left(2^{n}\right)$ & (n) & Size in $\mathbf{m m}^{3}$ \\
\hline Ref. [13] & $\begin{array}{c}\text { 1-WB. } \\
\text { 2-WB with filtering of } 5.5 \text { WLAN } \\
\text { band GHz. } \\
\text { 3-WB with filtering of X-band } 7.5 \\
\text { GHz. } \\
\text { 4-WB with filtering of WLAN } 5.5 \\
\text { GHz and X-band } 7.5 \mathrm{GHz} \text {. }\end{array}$ & 3 & $40 \times 30 \times 0.8$ \\
\hline Ref. [14] & $\begin{array}{l}\text { 1-WB with filtering of WLAN band } \\
\text { 2.4 GHz. } \\
\text { 2-WB with filtering of WiMAX band } \\
3.5 \mathrm{GHz} \text {. } \\
\text { 3-WB with filtering of WLAN band } 5 \\
\text { GHz. } \\
\text { 4-WB with filtering of ITU band } 8 \\
\text { GHz } 5 \text {. }\end{array}$ & 5 & $25 \times 25 \times 0.8$ \\
\hline Ref. [15] & $\begin{array}{c}\text { UWB. } \\
\text { UWB with filtering of WLAN } 5.5 \\
\text { GHz, RFID } 6.8 \mathrm{GHz} \text { X band } 11.5 \\
\text { GHz. } \\
\text { UWB with filtering of WLAN } 5.5 \\
\text { GHz, X band } 11.5 \mathrm{GHz} \text {. } \\
\text { UWB with filtering of X band } 8.7 \\
\text { GHz. } \\
\text { UWB with filtering of RFID band } 6.8 \\
\text { GHz X band } 8.7 \mathrm{GHz} \text {. } \\
\text { UWB with filtering of RFID band } 6.8 \\
\text { GHz. }\end{array}$ & 4 & $30 \times 31 \times 0.8$ \\
\hline $\begin{array}{c}\text { The antenna } \\
\text { of the } \\
\text { proposed } \\
\text { work }\end{array}$ & $\begin{array}{c}\text { 1-UWB. } \\
\text { 2-WB with filtering of WiMAX band } \\
3.5 \mathrm{GHz} \text {. } \\
\text { 3-WB with filtering of lower-band } \\
\text { WLAN } 5.2 \mathrm{GHz} \text {. } \\
\text { 4-WB with filtering of ITU band } 8.2 \\
\text { GHz. } \\
\text { 5-WB with filtering of WiMAX band } \\
3.5 \mathrm{GHz} \text { and } 5.2 \mathrm{GHz} \text {. } \\
\text { 6-WB with filtering of WiMAX band } \\
\text { 3.5 GHz and ITU band } 8.2 \mathrm{GHz} \text {. } \\
\text { 7-WB with filtering of Lower-band } \\
\text { WLAN } 5.2 \mathrm{GHz} \text { and ITU band } 8.2 \\
\text { GHz. } \\
\text { 8-WB with filtering of WiMAX band } \\
\text { 3.5 GHz, lower-band WLAN } 5.2 \mathrm{GHz} \\
\text { and ITU band } 8.2 \mathrm{GHz} \text {. }\end{array}$ & 4 & $35 \times 35 \times 1.6$ \\
\hline
\end{tabular}

\section{CONCLUSIONS}

At this work, eight reconfigurable filtering states has been integrated in a simple planar monopole UWB antenna. The design has been done by two simulation software, where the results obtained by both confirm each other. The performance has been compared with those obtained in previous works, where the proposed antenna has showed the highest number of operational modes. The proposed structure is suitable for application in UWB systems where it can solve interference problem, as well, it can be used for applications where reconfigurable bandwidth is required such as in cognitive radio systems.

\section{REFERENCES}

[1] UFC Commission. FCC Revision of part 15 of the commission's rules regarding ultra-wideband transmission systems: First report and order.
Technical Report, 2002.

[2] D. Valderas, J. I. Sancho, D. Puente, C. Ling, X. Chen, Ultrawideband Antennas. Imperial College Press, 2010. DOI $10.1142 / \mathrm{p} 684$.

[3] M. Ur-Rehman, QH. Abbasi, M. Akram, C. Parini, "Design of bandnotched ultra wideband antenna for indoor and wearable wireless communications", IET Microwaves, Antennas \& Propagation, vol. 9 no. 3, pp. 243-51, 2014. DOI: 10.1049/iet-map.2014.0378.

[4] M. Koohestani, N. Pires, A. K. Skrivervik, A. A. Moreira, "Bandreject ultra-wideband monopole antenna using patch loading", Electronics letters, vol. 48, no. 16, pp. 974-975, 2012. DOI: 10.1049/el.2012.1771

[5] T. D. Nguyen, D. H. Lee, H. C. Park, "Design and analysis of compact printed triple band-notched UWB antenna", IEEE antennas and wireless propagation letters, vol. 10, pp. 403-406, 2011. DOI: 10.1109/LAWP.2011.2147270.

[6] K. Luo, W. P. Ding, W. Q. Cao, "Compact monopole antenna with triple band-notched characteristics for UWB applications", Microwave and Optical Technology Letters, vol. 56, no. 4, pp. 822827, 2014. DOI: $10.1002 / \mathrm{mop} .28223$.

[7] D. E. Anagnostou, M. T. Chryssomallis, B. D. Braaten, J. L. Ebel, N. Sepulveda, "Reconfigurable UWB antenna with RF-MEMS for ondemand WLAN rejection", IEEE Trans. Antennas and Propagation, vol. 62, no. 2, pp. 602-608, 2014. DOI: 10.1109/TAP.2013.2293145.

[8] A. M. Abbosh, "Design of a CPW-fed band-notched UWB antenna using a feeder-embedded slot-line resonator", International Journal of Antennas and Propagation, 2008, pp. 1-5. DOI $10.1155 / 2008 / 564317$.

[9] N. Sepulveda, D. E. Anagnostou, M. T. Chryssomallis, J. L. Ebel, "Integration of RF-MEMS switches with a band-reject reconfigurable ultra-wideband antenna on $\mathrm{SiO}_{2}$ substrate", in IEEE Antennas and Propagation Society Int. Symposium, 2010, pp. 1-4. DOI: 10.1109/APS.2010.5560968.

[10] S. Nikolaou, N. D. Kingsley, G. E. Ponchak, J. Papapolymerou, M. M. Tentzeris, "UWB elliptical monopoles with a reconfigurable band notch using MEMS switches actuated without bias lines", IEEE Trans on Antennas and Propagation, vol. 57, no. 8, pp. 2242-2251, 2009. DOI: 10.1109/TAP.2009.2024450.

[11] B. Badamchi, J. Nourinia, C. Ghobadi, A. V. Shahmirzadi, "Design of compact reconfigurable ultra-wideband slot antenna with switchable single/dual band notch functions", IET Microwaves, Antennas \& Propagation, vol. 8, no. 8, pp. 541-548, 2014. DOI: 10.1049/ietmap.2013.0311.

[12] N. Tasouji, J. Nourinia, C. Ghobadi, F. Tofigh, "A novel printed UWB slot antenna with reconfigurable band-notch characteristics", IEEE Antennas and wireless propagation letters, vol. 12, pp. 922925, 2013. DOI: 10.1109/LAWP.2013.2273452.

[13] P. Lotfi, M. Azarmanesh, E. Abbaspour- Sani, S. Soltani, "Design of very small UWB monopole antenna with reconfigurable band-notch performance", in IEEE Sixth Int. Symposium Telecommunications (IST 2012), 2012, pp. 102-105. DOI: 10.1109/ISTEL.2012.6482964.

[14] H. Oraizi, N. V. Shahmirzadi, "Frequency-and time-domain analysis of a novel UWB reconfigurable microstrip slot antenna with switchable notched bands", IET Microwaves, Antennas \& Propagation, 2017. DOI: 10.1049/iet-map.2016.0009.

[15] S. H. Zheng, X. Liu, M. M. Tentzeris, "Optically controlled reconfigurable band-notched UWB antenna for cognitive radio systems", Electronics Letters, vol. 50, no. 21, pp. 1502-1504, 2014. DOI: $10.1049 / \mathrm{el} .2014 .2226$.

[16] Y. Li, W. Li, Q. Ye, "A reconfigurable triple-notch-band antenna integrated with defected microstrip structure band-stop filter for ultrawideband cognitive radio applications", International Journal of Antennas and Propagation, 2013. DOI: 10.1155/2013/472645.

[17] M. Hicham, A. Zegadi, "Design of reconfigurable filtering based UWB antenna dedicated for radar applications", in IEEE Seminar Detection Systems Architectures and Technologies (DAT 2017), pp. 1-4, 2017. DOI: 10.1109/DAT.2017.7889162.

[18] Computer Simulation Technology. [Online]. Available: https://www.cst.com

[19] S. B. Cohn, "Slot line on a dielectric substrate", IEEE Trans on microwave theory and techniques, vol. 17, no. 10, pp. 768-778, 1969. DOI: 10.1109/TMTT.1969.1127058.

[20] Radio frequency components. [Online]. Available: https://www.infineon.com/cms/en/product/rf-wireless-control/rfdiode/rf-pin-diode/antenna-switch/bar50-02v/

[21] Higher Frequency Structure Simulator. [Online]. Available: http://www.ansys.com. 